International Journal of Engineering \&Technology, $7(3.12)(2018) 1098-1101$
International Journal of Engineering \& Technology
Website: $w$ ww.sciencepubco.com/index.php/IJET
Research paper

\title{
Fatigue Analysis of a Railway Steel Bridge
}

\author{
Kandagatla Viswanath ${ }^{1 *}$, M. Ravi Kumar ${ }^{2}$ \\ ${ }^{1,2}$ Department of Civil Engineering, Koneru Lakshmaiah Education Foundation, Vaddeswaram, Guntur, AP, India \\ *Corresponding author E-mail: ${ }^{1}$ viswanath.k995@gmail.com, ${ }^{2}$ mudragadaravikumar1216@gmail.com
}

\begin{abstract}
One of the significant means of transportation in India are railways and has many steel bridges which are very old having historical importance and their design period is terminating. To appraisal, the levels of damage for workable repairs, stands a tedious job for government authorities. The prediction of fatigue life of bridges are important because at present these are subjected to elephantine loads than the design loads and the environmental conditions boost these aspects to turn up fatigue life. This paper studies the analytical analysis of a steel railway bridge subjected to EURO and INDIAN fatigue loading to evaluate the fatigue life of a bridge and stresses are calculated from S-N curves by nominal stress method. The fatigue verification has been done by $\lambda$-coefficient method. Fatigue life of critical section was found out by sub-modelling the welded joint where the stress are maximum. The crack initiation starts at powerless members and propagates it along the section leads to fracture the entire structure under elastic behaviour. Hence, if the results of the critical section are satisfactory, it can be concluded that entire bridge is safe in fatigue point of view. INDIAN HM loadings generate more damage than EURO LM-71 loading.
\end{abstract}

Keywords: critical section; fatigue life; Nominal Stress Method; steel bridges; $\lambda$-Coefficient method.

\section{Introduction}

In the 19th century, civil engineering saw an immense advancement but with a handful of problems, a lot of powerful collapses took place and Steel structures were not exempted from this. Considering the case of steel structures recent studies by Emrani and Aygul [1] indicates most of the failure is by repetitive loads i.e. fatigue. The Fatigue spoilage is more for railway bridges than for $\mathrm{road} / \mathrm{highway}$ bridges. In the frame of railway bridges, the freight traffic is the one that increases more concerns from the fatigue scenario. The panorama of current metallic bridges was classified into bolted/welded and riveted metallic bridges. The fatigue concern is concentrated on the steel components [2]. As the fatigue has become the failure scenario the critical plane approach is the method that precisely finds out the stresses of the powerless sections, though c-s criteria give the finest set of results, it is a tedious work. The smarter way for quick and basic appraisal of the fatigue is global approaches, which can basically identify the highly damaged influential connection in its own precise approach concerning its endemic accuracy.

As the modern design changes increase the appraisal for fatigue, it is a demanding aspect for the engineers as the loads on the bridges are multi-axial in nature. The burdens refined at the welded joints are principal because of this multi-axial situation. Limiting the study to the fundamental approach which is adopted sophisticatedly and the analysis is accomplished with uniaxial loads with various speeds in numerical consideration. Several investigations of different steel bridges are analysed by the load histories and field measurements, taking the span as a parameter Philbrick et al.

[3] carried out their study by the same field aspects, Caglayan et al. [4] appraised for the influencing factors of fatigue for a preexisting bridge in Istanbul. Under different loading criteria Banja- ra et al. [5] studied the efficacy of models by simulation under field measurements with different train speeds.

All the research works are centred on field parameters. There are very few studies in for the comparison of two different code provisions and in turn comparison with the INDIAN codes is not much progressed. The present study shows the heterogeneity between INDIAN and EURO codes for fatigue loadings and speed aspects are taken into deliberation.

\section{Bridge Description}

A uni spanned clear to sky deck U through plate girder RailwayBridge located in Berlin is explored during this study. The bridge is in good status quo. The bridge is designed by taking all the load combinations into the picture. Finalising the model with two longitudinal main girders on either side with abutments at $25 \mathrm{~m}$ (82.5ft) spanning. The main members are backed by inverted $\mathrm{T}$ girders in the entire length of the bridge at a spacing of $700 \mathrm{~mm}$. the central width of the bridge is $4.6 \mathrm{~m}(15.18 \mathrm{ft})$. The main member and cross members are linked up with vertical stiffeners distributed at $1400 \mathrm{~mm}$. the overall height of the main girder is $1770 \mathrm{~mm}$ (top flange to bottom flange) with a web thickness of 40 $\mathrm{mm}$. the $\mathrm{t}$ girder with $350 \mathrm{~mm}$ height. The deck is rested on the inverted $\mathrm{T}$ girders with a thickness of $20 \mathrm{~mm}$. the bridge is simply supported on the abutments. $\mathrm{U}$ frame bridges are used over little passage distances and can handle the load by its $U$ frame system. The properties of members are listed in Table 1. The design model is exactly simulated and the analysis is effectuated.

Table 1: properties of members

\begin{tabular}{|c|c|c|}
\hline S.No & Property & Value \\
\hline 1 & Moment of inertia, I of main member & $6.345 \mathrm{E}+10 \mathrm{~mm}^{4}$ \\
\hline 2 & Section Modulus, Z of main member & $71683615 \mathrm{~mm}^{3}$ \\
\hline 3 & Moment of inertia, I of c/s girder & $146500000 \mathrm{~mm}^{4}$ \\
\hline
\end{tabular}




\section{\begin{tabular}{l|l|r}
4 & Section Modulus, Z of c/s girder & $1449060 \mathrm{~mm}^{3}$
\end{tabular}}

\section{Modelling}

To arbitrate precisely the effects from the action forces e.g. stresses, internal forces, etc. rooted from actions, the load acting path should be properly modelled from its root to tip (i.e. origin to supports). The bridge dimensions are seized and the 3D model of railway steel bridge is modelled directly in ANSYS Workbench 18.1 as shown in Fig.1. which gives the feasibility for submodelling without any import. The load controlling girders are modelled first and extended to its dimensions and the cross girders are lined attaching with the main girders. For the stability of the bridge, the stiffeners are added to the main girders as per the design interval. Hence the final values are ultraprecise.

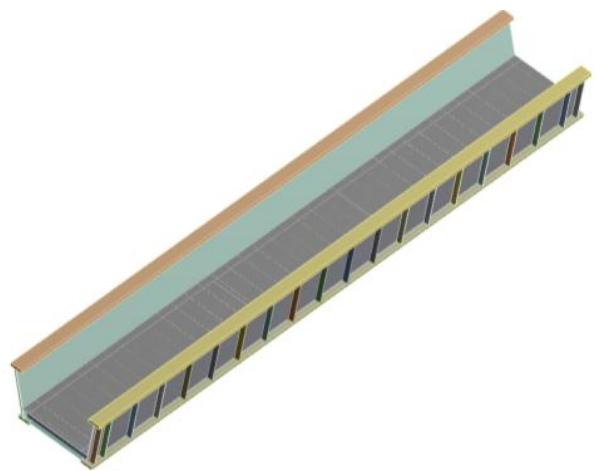

Fig. 1: Model of bridge

The background of workbench runs with the beam and shell elements that assign the structural steel property to the bridge having 8 nodes beam elements. Not only the accurate modelling of the bridge gives accurate results but the meshing also boost the accuracy as the FEM-based approach is dividing the model into finite element parts and analysing each, without compromising for time the model meshes with tetrahedron method and for curvature proximity, the model has finely meshed as shown in Fig.2. Indicating a proof that the aspect ratio is nearer to 20 .
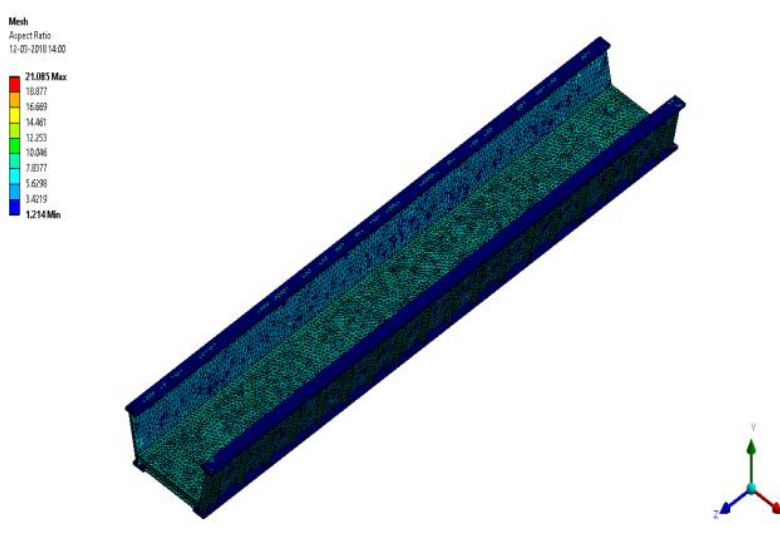

Fig. 2: Finely meshed bridge model

\subsection{Mode Shapes and Frequencies}

Ascertaining the modal constraints, to be precise the natural frequencies, and mode shapes, has turn out to be a major concern of structural dynamicists. This path of exploration is represented as modal analysis. After accurately simulating the model and meshing, to validate the structure modal analysis is being carried out. The modes shapes as shown in Fig. 3. Indicates the bridge is laterally less stiff.
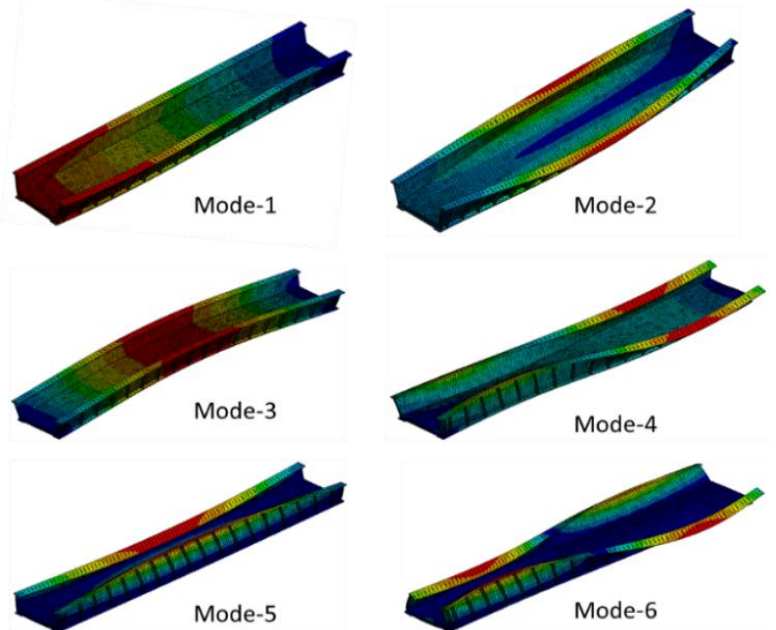

Fig. 3: Mode Shapes

For stiffer bridges, the frequencies are more e.g. steel bridges. The results as shown in Table 2. Indicate that the bridge is stiffer enough to take the loads. The results from the modal analysis are helpful in the updataion of the model.

Table 2: Frequencies

\begin{tabular}{|c|c|c|}
\hline S.No & Mode & Frequency $(\mathrm{Hz})$ \\
\hline 1 & 1 & 5.336 \\
\hline 2 & 2 & 9.629 \\
\hline 3 & 3 & 10.022 \\
\hline 4 & 4 & 19.102 \\
\hline 5 & 5 & 22.103 \\
\hline 6 & 6 & 22.729 \\
\hline
\end{tabular}

\section{Methodology}

Generally, the appraisal methods for assessing the serviceability of steel fabrications are based on stresses, strains, or stress magnitude factors. The basic and the simplest common method also termed as global method i.e. the nominal stress method [6]. This method primarily relies on the intermediate stress in the investigated cross section considering the behaviour under linear elasticity. The nominal stress doesn't take the deliberation of stress rising effect from welded parts. The nominal stress methodology is not workable on more complex geometric structures. In the nominal stress method, the fatigue verification is done by $\lambda$-coefficient method is used where it takes the partial factors of fatigue into account and the different $\lambda$ factors are taken according to the euro code specifications. The overall methodology is shown in Fig. 4.

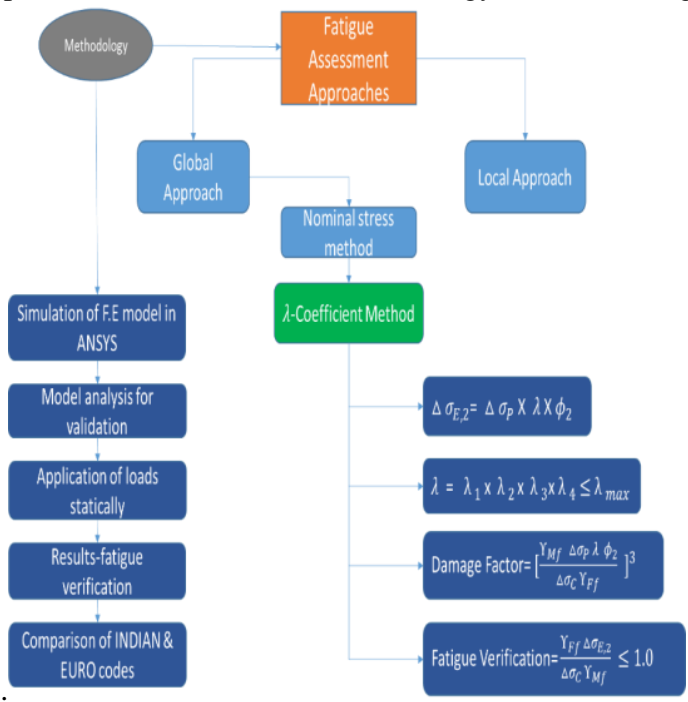

Fig. 4: Flowchart of methodology 


\subsection{Loadings}

Fatigue loading is the most significant parameter that influencing the fatigue strength of steel structures/members. The fatigue loading causes repetitive or fluctuating stress in the components of the structure due to the variation in the application of loads. LM71 loadings from EN 1993 1-9, 2005 [7] as shown in Fig. 5. The standard axle loadings used for the fatigue appraisal which is rooted up from standard traffic data applied statically. The main loadings from Indian scenario are the HM loadings from indian bridge rules[8] with 30T axle load as shown in Fig. 6. The damage and fatigue life depends on the traffic mixes i.e. the number of load spectra acting. Here normal traffic (25T) and heavy traffic (30T) are considered

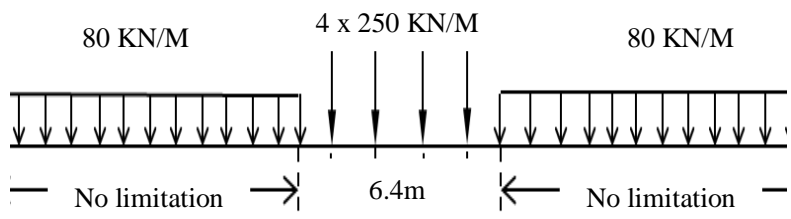

Fig. 5: Lm-71 euro loading

\section{ELECTRC LOCOS (WAGGC TYPE)}

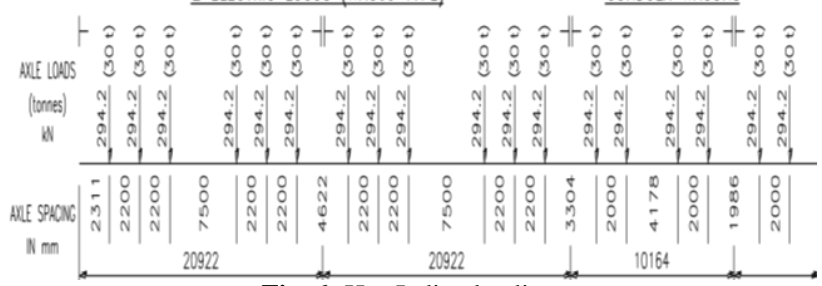

Fig. 6: Hm-Indian loading

\subsection{Connection Details}

The connection between the main girders and cross girder are made of welded type and so the welded connections are more subjected to fatigue. Here 4 connection details are listed as shown in Fig. 7.

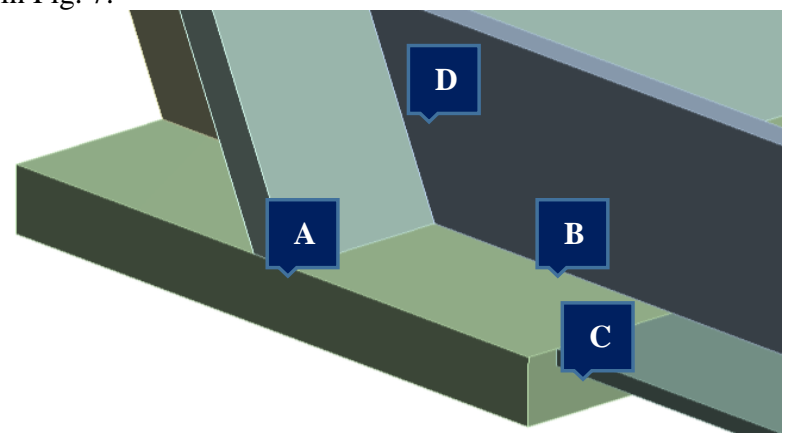

Fig. 7: Connection details
The description of the connection details are listed in Table 3.

Table 3: Type of connection

\begin{tabular}{|c|c|l|}
\hline S.No & $\begin{array}{c}\text { Connection } \\
\text { number }\end{array}$ & \multicolumn{1}{|c|}{ Construction detail } \\
\hline 1 & $\mathrm{~A}$ & $\begin{array}{l}\text { Toe of the web-to-tension flange weld in the } \\
\text { main girder }\end{array}$ \\
\hline 2 & $\mathrm{~B}$ & $\begin{array}{l}\text { Toe of the web-to-tension flange weld in } \\
\text { cross girder }\end{array}$ \\
\hline 3 & $\mathrm{C}$ & Toe of the flange-to-flange weld connection \\
\hline 4 & $\mathrm{D}$ & $\begin{array}{l}\text { Toe of the web-to-web weld b/w cross \& } \\
\text { main girder }\end{array}$ \\
\hline
\end{tabular}

\section{Results}

As per the $\lambda$-coefficient method, the LM-71 and HM loadings are applied statically i.e. non-variable proportional loading. Accordingly, the stress from the s-n curves corresponding to its detailed category at $2 \times 10^{6}$ cycles was related to the analytical stresses as in Fig. 8, for the critical detailed connection. The damage done to the members by the HM and LM-71loadings are appraised and listed as shown in Tables $4-5$. The damage should be $<1$ in order to satisfy the design life.

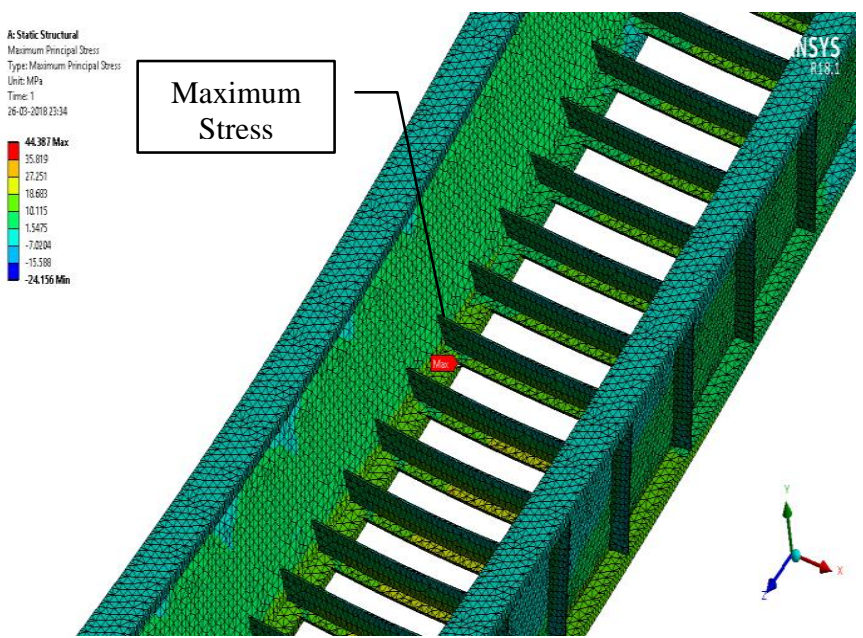

Fig. 8: Maximum stress observed in cross girder

Table 4: Results for HM loadings

\begin{tabular}{|c|c|c|c|c|c|c|c|c|c|}
\hline \multirow{3}{*}{ S.No } & \multirow{3}{*}{$\begin{array}{l}\text { Speed } \\
\text { kmph }\end{array}$} & \multicolumn{8}{|c|}{ Connection details } \\
\hline & & \multicolumn{2}{|c|}{$\mathrm{A}$} & \multicolumn{2}{|c|}{$\mathrm{B}$} & \multicolumn{2}{|c|}{$\mathrm{C}$} & \multicolumn{2}{|c|}{$\mathrm{D}$} \\
\hline & & Damage & Years & Damage & Years & Damage & Years & Damage & Years \\
\hline 1. & 160 & 0.068 & 1454.4 & 0.023 & 4212.7 & 1.392 & 71.97 & 0.113 & 854.17 \\
\hline 3. & 120 & 0.060 & 1659.5 & 0.020 & 4805.7 & 1.218 & 82.08 & 0.10 & 974.75 \\
\hline 4. & 100 & 0.056 & 1764.7 & 0.019 & 5108.9 & 1.14 & 87.02 & 0.096 & 1035.7 \\
\hline
\end{tabular}

Table 5: Results for LM-71loadings

\begin{tabular}{|c|c|c|c|c|c|c|c|c|c|}
\hline \multirow{3}{*}{ S.No } & \multirow{3}{*}{$\begin{array}{l}\text { Speed } \\
\text { kmph }\end{array}$} & \multicolumn{8}{|c|}{ Connection details } \\
\hline & & \multicolumn{2}{|c|}{$\mathrm{A}$} & \multicolumn{2}{|c|}{ B } & \multicolumn{2}{|c|}{$\mathrm{C}$} & \multicolumn{2}{|c|}{$\mathrm{D}$} \\
\hline & & Damage & Years & Damage & Years & Damage & Years & Damage & Years \\
\hline 1. & 160 & 0.047 & 2110.0 & 0.012 & 7984.6 & 1.184 & 84.12 & 0.107 & 945.35 \\
\hline 2. & 140 & 0.044 & 2257.39 & 0.011 & 8542.2 & 1.116 & 90.7 & 0.098 & 1011.4 \\
\hline 3. & 120 & 0.041 & 2407.11 & 0.0109 & 9108.2 & 1.041 & 95.93 & 0.092 & 1078.43 \\
\hline 4. & 100 & 0.039 & 2558.61 & 0.0103 & 9682.05 & 0.981 & 102.03 & 0.087 & 1146.6 \\
\hline
\end{tabular}




\section{Conclusions}

It was identified that the bottom flange of the 14 cross girder (under detail C) fails as the maximum stress develops at that location and the corresponding cross girders track the failure path. Different locomotives cross over the bridge with different speeds and it is also an influential parameter which directly links with the damage were also taken into deliberation. The loadings on the railway bridge are in multi-axial scenario for which CS-criteria can deeply predict its life most precisely. But still $\lambda$-coefficient methodology is a simple quick way to identify the powerless members without prolongation and the following conclusions were made.

- The fatigue life of the considered bridge is predicted by application of EURO and INDIAN fatigue loadings.

- The design life of bridge was assumed as 100 years.

- Fatigue life of the considered bridge is 84 years for EURO loading and 72years for INDIAN HM loadings.

- Considered Indian loads are heavy so that these loads generate more damage compared to the Euro loadings.

- Bottom flange of cross girder was identified as the most critical connection in the bridge. Hence, considered bridge may not be implemented in India but still it can be possible through some modifications in weld connections.

- The bridge can be adapted for temporary construction.

- This methodology can be used for the fatigue life prediction of other railway bridges.

\section{Acknowledgement}

The author wishes to thank Asst. Prof. M. Ravi Kumar for his valued guiding and comments through out the duration of the research.

\section{References}

[1] M. Emrani, M. Aygul, "Fatigue Design of Steel and Composite Bridges", 10, Department of Civil and Environmental Engineering, Chalmers University of Technology, Sweden, 2014, pp.156.

[2] R. H. Bundesanstalt, "Assessment of existing steel structures : Recommendations for estimation of Remaining Fatigue Life", 3, European Commission, 2014.

[3] T.W. Philbrick, G.W. Zodo, S.D. Schiff, (1995), "Fatigue assessment of through plate girder railway bridges", Journal of Structural Engineering, Vol.121, No.11, pp.1613-1619.

[4] B.O. Caglayan, K. Ozakgul, O. Tezer, (2009), "Fatigue life evaluation of a through-girder steel railway bridge", Engineering Failure Analysis, Vol.16, No.3, pp. 765-774.

[5] N.K. Banjara, S. Sasmal, (2014), "Remaining fatigue life of stee railway bridges under enhanced axle loads", Structure and Infrastructure Engineering, Vol.10, No.2, 213-224.

[6] M. Aygul, "Fatigue Analysis of Welded Structures Using the Finite Element Method, 4, Department of Civil and Environmental Engineering”, Chalmers University of Technology, Sweden, 2012, pp.156.

[7] European Union, EN 1993-1-9 (2005), Eurocode 3: Design of steel structures - Part 1-9: Fatigue

[8] Bridge Rules (1964), Ministry of Railways, Govt. of India, Revised.

[9] K. C. Misra, D. Panda, S. Bhattacharjya, (2014), "Fatigue life assessment of century old railway bridge in India", International Journal of Innovative Research in Science, Vol.3, No.3, pp.1080310808 .

[10] F.N. Leitao, J.G.S. Silva, S.A.L Andrade, (2013), "Fatigue analysis and life prediction of composite high-way bridge decks under traffic loading", Latin American Journal of Solids and Structures, Vol.10, pp.505-522.

[11] A.R. Ragaby, E.E. Salakawy, B. Benmokrane, (2004), "Concrete bridge deck slabs reinforced with FRP composite bars, Journal of Composites for Construction”, Vol.9, No. 2, pp.21-27.
[12] M. Chiewanichakorn, A.J. Aref, S. Alampalli, (2007), "Dynamic and fatigue response of a truss bridge with fiber reinforced polymer deck", International journal of Fatigue, Vol.29, No. 8, pp.14751489.

[13] K. Nallasivam, S. Talukdar, A. Dutta, (2008), "Fatigue life prediction of horizontally curved thin walled box girder steel bridges", Structural Engineering and Mechanics, Vol. 28, No.4, pp. 387-410.

[14] H. Agerskov, J.A. Nielsen, (1999), "Fatigue in steel highway bridges under random loading", Journal of Structural Engineering, Vol.125, No.2, pp.152-162

[15] R.K. Goel, A.K. Pandey, S.D. Kumar, and S.N. Gupta, "Guidelines for assessment of residual fatigue life of steel girder bridges", BS91, Research Designs \& Standards Organization, Lucknow, 2008.

[16] M. Heshmati, "Fatigue life assessment of bridge details using finite element method", 03, Department of Civil and Environmental Engineering, Chalmers University of Technology, Sweden, 2012.

[17] British Standards Institution, BS: 5400: Part 10 (1980), Steel, Concrete and Composite Bridges-Part10: Code of Practice for Fatigue. 